\title{
Distribuição estereoespecífica de lipídios estruturados a partir de gorduras de palma, palmiste e triacilgliceróis de cadeia média
}

\author{
Denise D'Agostini*, Luiz Antonio Gioielli \\ Departamento de Tecnologia Bioquímico-Farmacêutica, Faculdade de Ciências Farmacêuticas, \\ Universidade de São Paulo
}

*Correspondência:

Luiz Antonio Gioielli

Depto. de Tecnologia Bioquímico-

Farmacêutica

Faculdade de Ciências Farmacêuticas

Universidade de São Paulo

Av. Prof. Lineu Prestes, 580, Bloco 16

05508-900 - São Paulo, SP, Brasil

E-mail: lagio@usp.br
Por meio de interesterificação química foram sintetizados lipídios estruturados a partir das gorduras de palma, palmiste e triacilgliceróis de cadeia média. O objetivo deste trabalho foi verificar a distribuição estereoespecífica dos ácidos graxos nos lipídios estruturados. Foi possível comprovar a ocorrência da interesterificação através da hidrólise enzimática, que permitiu conhecer a composição dos ácidos graxos em posições específicas dos triacilgliceróis. Foram estudadas 10 amostras, representadas por 3 amostras individuais, 3 misturas binárias e 4 misturas ternárias. As amostras foram submetidas à hidrólise com lipase pancreática suína à temperatura de $40{ }^{\circ} \mathrm{C}$ e posteriormente analisadas por cromatografia gasosa quanto à composição em ácidos graxos na posição sn-2. A partir dos resultados foram calculados os grupos de triacilgliceróis nas amostras individuais e nas misturas antes e após a reação de interesterificação, utilizando as teorias 1,3-random 2-random e 1,2,3-random. Os resultados demonstraram que antes do rearranjo ao acaso houve preferência do ácido oléico pela posição sn-2, enquanto que os ácidos palmítico e esteárico distribuíram-se principalmente pelas posições sn-1 e sn-3. Nos lipídios estruturados, os ácidos graxos saturados aumentaram sua participação na posição central do triacilglicerol, enquanto que os ácidos graxos insaturados apresentaram diminuição nesta mesma posição.
Unitermos:

- Hidrólise enzimática

- Gordura de palma

- Gordura de palmiste

- Triacilgliceróis de cadeia média

- Interesterificação química

- Lipídios estruturados

\section{INTRODUÇÃO}

Lipídios estruturados são triacilgliceróis modificados obtidos através de interesterificação química ou enzimática, com a finalidade de alterar a composição em ácidos graxos e/ou sua distribuição posicional na molécula de glicerol. São sintetizados com o objetivo de se obter lipídios nutracêuticos, que podem proporcionar benefícios específicos para a saúde, bem como melhorar ou modificar as características físicas e químicas dos triacilgliceróis, além de modificar ou incrementar as propriedades nutricionais do alimento (Gioielli, 2002; Yankah, Akoh, 2000). Os lipídios estruturados tornaram-se interessantes desde que as aplicações nutricionais dos triacilgliceróis de 
cadeia média foram descritas. Recentemente, lipídios estruturados específicos têm atraído a atenção tanto por suas aplicações quanto pela produção (Xu et al., 1998).

Lipídios estruturados específicos, tais como os obtidos através de misturas físicas de óleos vegetais convencionais e triacilgliceróis de cadeia média, têm sido amplamente utilizados em estudos de absorção e empregados em nutrição clínica, justamente devido às propriedades benéficas dos ácidos graxos de cadeia média sobre a saúde (D’Agostini et al., 2001; Mu, Xu, Hoy, 1998). Os ácidos graxos de cadeia média podem ser incorporados a gorduras e óleos formando lipídios estruturados que irão conter ácidos graxos de cadeia média nas posições sn-1 e sn-3 e um ácido graxo de cadeia longa na posição sn-2. É benéfico incorporar ácidos graxos de cadeia longa insaturados na posição sn-2 devido à baixa atividade da lipase pancreática com relação a estes ácidos graxos quando eles estão presentes nas posições sn-1 e sn-3 dos triacilgliceróis. Na posição sn-2 os ácidos graxos de cadeia longa insaturados são mais biodisponíveis, devido à ação das lipases (Carnielly et al., 1995), visto que são mais facilmente absorvidos como 2-monoacilgliceróis. Lipídios com esta composição são mais completos e nutricionalmente benéficos como alimento, sendo bem tolerados e mais rapidamente metabolizados que os triacilgliceróis de cadeia longa, quando incorporados às emulsões lipídicas administradas em pacientes hospitalizados, uma vez que podem fornecer ácidos graxos de cadeia média como uma rápida fonte de energia, e ácidos graxos de cadeia longa como ácidos graxos essenciais (Sandstrom et al., 1993). Os ácidos graxos esterificados na posição sn2 são facilmente absorvidos pelo organismo, independentemente do tipo de ácido graxo esterificado naquela posição (Haumann, 1997).

Na última década, a interesterificação tem surgido como uma ferramenta imprescindível das indústrias na síntese de óleos e gorduras com características e funcionalidades específicas. Este processo tecnológico pode ser alternativo à hidrogenação, principalmente devido à ausência de ácidos graxos trans nos produtos e obtenção de lipídios com características e funções únicas (Haumann, 1994). Entre os parâmetros utilizados nas avaliações da interesterificação destacam-se os métodos cromatográficos, incluindo-se entre eles a composição em ácidos graxos do carbono sn-2 e a composição triacilglicerídica (Gunstone, Harwood, Padley, 1994).

Os óleos vegetais naturais apresentam distribuições não-randômicas dos grupamentos acil nas posições sn-1, sn-2 e sn-3 dos triacilgliceróis, que podem afetar suas propriedades físicas e sua estabilidade oxidativa (Harp, Hammond, 1998). Decker (1996) estudou o papel das posições estereoespecíficas de ácidos graxos saturados sobre a nutrição. Os ácidos graxos saturados nas posições sn-1 e sn-3 dos triacilgliceróis podem exibir diferentes padrões metabólicos devido à sua baixa absorção. Isto significa que dietas à base de gorduras contendo ácidos graxos saturados primariamente nas posições sn-1 e sn-3 (tais como manteiga de cacau, óleo de coco e óleo de palma) podem apresentar conseqüências biológicas muito diferentes das gorduras nas quais os ácidos graxos saturados estão primariamente na posição sn-2 (tais como a gordura do leite, a banha e o toucinho). Diferenças na localização estereoespecífica de ácidos graxos devem, por essa razão, ser uma importante consideração no planejamento e interpretação de estudos em nutrição e na elaboração de produtos alimentícios especiais.

A hidrólise enzimática de triacilgliceróis através da lipase pancreática é uma técnica utilizada para obter 2monoacilgliceróis. A análise da composição em ácidos graxos da posição sn-2 dos triacilgliceróis é geralmente empregada para avaliar a distribuição posicional dos ácidos graxos. A partir destes dados, o percentual de gordura interesterificada presente em uma determinada gordura ou produto gorduroso (margarina, por exemplo) pode ser estimado (Mansour, Sinclair, 1993). A ressonância nuclear magnética de alta resolução (RNM) também pode ser utilizada na determinação estrutural de ácidos graxos, seus análogos e derivados, bem como na análise estrutural de triacilgliceróis, incluindo a análise quantitativa de misturas lipídicas. Segundo Lie Ken Jie e Mustafa (1997), este método permite determinar a composição de grupos acil saturados e dos ácidos graxos oléico e linoléico nas posições sn-1,3 e sn-2 dos triacilgliceróis de óleos vegetais. Exceto pela falta de diferenciação dos ácidos graxos saturados, a técnica de ressonância nuclear magnética do ${ }^{13} \mathrm{C}$ fornece a mesma informação que a trabalhosa técnica de hidrólise enzimática seguida da análise de ácidos graxos.

George e Arumughan (1993) pesquisaram a distribuição posicional dos ácidos graxos nos triacilgliceróis do óleo do fruto da palma em desenvolvimento. Foram encontradas maiores quantidades de ácidos graxos saturados esterificados nas posições sn-1,3 e maiores teores de ácidos graxos insaturados na posição sn-2 dos triacilgliceróis. Os índices mais elevados de incorporação de ácido palmítico nas posições 1 e 3 foram observados durante a fase ativa da síntese dos triacilgliceróis, enquanto que o ácido oléico exibiu tendência contrária.

O objetivo deste trabalho foi verificar a distribuição estereoespecífica dos ácidos graxos nos lipídios estruturados obtidos a partir das gorduras de palma, palmiste e triacilgliceróis de cadeia média. 


\section{MATERIAL E MÉTODOS}

\section{Material}

Foram utilizadas gorduras vegetais refinadas de palma e de caroço de palma (gentilmente cedidas pela empresa Agropalma S.A.) e triacilgliceróis de cadeia média (Trigliceril CMâ), comercializados pela empresa Support Produtos Nutricionais Ltda. Foram efetuadas misturas com estes três componentes em proporções variadas conforme mostra a Tabela I. Para a hidrólise enzimática foi utilizada a lipase pancreática de suínos (Tipo II, bruta) da empresa Sigma, com atividade enzimática de 220 unidades/mg de proteína. Uma unidade hidrolisa 1,0 microequivalente de ácido graxo de óleo de oliva em uma hora, em $\mathrm{pH}$ 7,7.

\section{Métodos}

\section{Composição em ácidos graxos}

A análise de ácidos graxos foi realizada em cromatógrafo a gás Varian GC, modelo 3400 CX, equipado com detector de ionização de chama e integrador eletrônico, modelo CG-300. Foi utilizada coluna capilar de sílica fundida VA-WAX (Varian), com 30 metros de comprimento x $0,25 \mathrm{~mm}$ de diâmetro interno e contendo $0,25 \mu \mathrm{m}$ de polietilenoglicol. As condições foram: injeção split, razão de $50: 1$; temperatura da coluna : $150^{\circ} \mathrm{C}$ por 11 minutos, programada até $210^{\circ} \mathrm{C}$ numa razão de $3^{\circ} \mathrm{C}$ por minuto; gás de arraste: hélio, numa vazão de $1,5 \mathrm{~mL}$ por minuto; gás make-up: hélio a $30 \mathrm{~mL}$ por minuto; temperatura do injetor: $250{ }^{\circ} \mathrm{C}$; temperatura do detector: $280^{\circ} \mathrm{C}$. A composição qualitativa foi determinada por comparação dos tempos de retenção dos picos com os dos respectivos padrões de ácidos graxos. A composição quantitativa foi realizada por normalização de área, sendo expressa como porcentagem em massa (D'Agostini, Ferraz, Gioielli, 2000; D'Agostini, Gioielli, Ferraz, 2000; D'Agostini et al., 2001a).

\section{Hidrólise enzimática}

Foram realizados testes de hidrólise enzimática com lipase pancreática para determinação do tempo necessário de incubação para se atingir cerca de $60 \%$ de hidrólise. Para o lote de enzima utilizado, este tempo foi de $30 \mathrm{mi}$ nutos, à temperatura de $40{ }^{\circ} \mathrm{C}$, utilizando $1 \mathrm{mg}$ de lipase (Christie, 1982). Após a hidrólise, a técnica envolveu a separação por cromatografia em camada delgada dos 2monoacilgliceróis formados. A banda referente aos 2monoacilgliceróis foi isolada e a composição em ácidos graxos determinada por cromatografia gasosa. A partir dos resultados obtidos foram calculados os grupos de triacilgliceróis nas amostras individuais e nas misturas antes e após a interesterificação química, utilizando as teorias de distribuição 1,3-random 2-random (para as gorduras naturais) e 1,2,3-random (para os lipídios estruturados).

\section{Interesterificação}

As amostras foram previamente fundidas em forno de microondas até a completa fusão dos cristais (60-70 $\left.{ }^{\circ} \mathrm{C}\right)$. A seguir, $320 \mathrm{~g}$ de cada amostra foram secas em evaporador rotativo durante $30 \mathrm{~min}$, à temperatura entre 90-95 ${ }^{\circ} \mathrm{C}$. Posteriormente, foram adicionados $0,75 \%$ de catalisador (metóxido de sódio). A reação de

TABELA I - Planejamento experimental das misturas de gorduras de palma, palmiste e triacilgliceróis de cadeia média

\begin{tabular}{cccc}
\hline AMOSTRA $\left(\mathrm{N}^{\circ}\right)$ & \multicolumn{3}{c}{ COMPONENTES (PROPORÇÃO EM MASSA) } \\
\cline { 2 - 4 } & Triacilgliceróis de cadeia média & Gordura de palma & Gordura de palmiste \\
\hline 1 & 1 & 0 & 0 \\
2 & 0 & 1 & 0 \\
3 & 0 & 0 & 1 \\
4 & $1 / 2$ & $1 / 2$ & 0 \\
5 & $1 / 2$ & 0 & $1 / 2$ \\
6 & 0 & $1 / 2$ & $1 / 2$ \\
7 & $1 / 3$ & $1 / 3$ & $1 / 3$ \\
8 & $2 / 3$ & $1 / 6$ & $1 / 6$ \\
9 & $1 / 6$ & $2 / 3$ & $2 / 3$ \\
10 & $1 / 6$ & $1 / 6$ & \\
\hline
\end{tabular}


interesterificação foi efetuada sob pressão reduzida (56 $\mathrm{mm}$ de $\mathrm{Hg}$ ), à temperatura entre 60 a $65^{\circ} \mathrm{C}$ durante 60 min, sob agitação. Ao final da reação, foram adicionados $3 \mathrm{~mL}$ de água destilada com o propósito de inativar o catalisador. Após adição de kieselgur e sulfato de sódio, as amostras foram filtradas a quente com papel de filtro (D’Agostini et al., 2001).

\section{RESULTADOS E DISCUSSÃO}

A Tabela II apresenta a composição em ácidos graxos das gorduras de palma, palmiste e triacilgliceróis de cadeia média e das respectivas misturas binárias e ternárias. Estes resultados exprimem a média de duas determinações. Os lipídios estruturados obtidos por interesterificação química apresentam a mesma composição em ácidos graxos que as amostras ou misturas originais, uma vez que os ácidos graxos não são alterados por este processo de modificação lipídica. Os resultados da Tabela II indicam que, de modo geral, os dados estão de acordo com os limites encontrados na literatura consultada e dentro das especificações comerciais dos fabricantes (Zeitoun, 1993; Goh, 1994; Gunstone, Harwood, Padley, 1994; Antoniosi Filho, 1995; Noraini et al., 1995; Ong, Choo, Ooi, 1995; Lipp, Anklam, 1998; Grimaldi, 1999). As características de identidade e qualidade do óleo de palma e do óleo de palmiste são estabelecidas pela legis- lação brasileira (Brasil, 1999). De acordo com Zeitoun et al. (1993), óleos ou gorduras contendo de 15 a 25\% de ácido palmítico são adequados para a produção de diversos tipos de margarinas, faixa presente nas amostras de números 4 e 7.

As Tabelas III e IV mostram a composição em ácidos graxos na posição sn-2 (\%) das amostras. Os valores obtidos na Tabela III, para as misturas, foram calculados, enquanto que os valores da Tabela IV foram obtidos experimentalmente. Comparando-se os resultados destas tabelas verifica-se que houve mudança posicional dos ácidos graxos na cadeia do glicerol após a interesterificação química. Devido à reação randômica, houve aumento do teor de ácido palmítico na posição central da molécula do triacilglicerol, para o óleo de palma, passando de $26,3 \%$ no óleo original para 49,1\% no óleo interesterificado, enquanto Grimaldi (1999) observou a variação deste ácido graxo na posição sn-2 de 19,3\% para 56,9\%, em função da interesterificação. De acordo com Kritchevsky et al. (2000), o aumento da concentração de ácido palmítico na posição sn-2 do triacilglicerol incrementa as propriedades aterogênicas da gordura. Este efeito tem sido observado com o toucinho, sebo e com os óleos de algodão e de palma.

Para a gordura de palmiste, os ácidos láurico e mirístico, embora saturados, apresentaram proporções bastante elevadas, quando comparadas aos demais ácidos

TABELA II - Composição em ácidos graxos das gorduras individuais e das misturas binárias e ternárias

\begin{tabular}{lcccccccccc}
\hline Ácidos & \multicolumn{10}{c}{ Amostras $\left(\mathrm{N}^{\circ}\right)$} \\
\cline { 2 - 10 } graxos (\%) & 1 & 2 & 3 & 4 & 5 & 6 & 7 & 8 & 9 & 10 \\
\hline 6:0 capróico & 0,2 & - & 0,2 & 0,1 & 0,2 & 0,1 & 0,1 & 0,2 & 0,1 & 0,1 \\
8:0 caprílico & 51,5 & - & 3,0 & 22,7 & 25,7 & 1,8 & 15,6 & 36,5 & 8,4 & 11,1 \\
10:0 cáprico & 47,5 & - & 3,2 & 20,8 & 22,7 & 1,8 & 14,4 & 30,4 & 7,2 & 9,8 \\
12:0 láurico & 0,8 & 0,2 & 46,3 & 0,4 & 26,0 & 25,0 & 17,0 & 9,3 & 8,2 & 34,4 \\
13:0 & - & - & 0,1 & - & - & - & - & - & - & - \\
14:0 mirístico & - & 0,8 & 15,7 & 0,7 & 8,7 & 8,3 & 6,0 & 3,2 & 3,3 & 10,9 \\
16:0 palmítico & - & 43,5 & 9,4 & 24,0 & 5,0 & 25,6 & 18,7 & 8,7 & 31,0 & 12,7 \\
16:1 palmitoléico & - & 0,1 & - & 0,1 & - & 0,1 & 0,1 & - & 0,1 & 0,1 \\
17:0 & - & - & - & 0,1 & - & 0,1 & 0,1 & - & 0,1 & - \\
18:0 esteárico & - & 4,4 & 2,5 & 2,4 & 1,3 & 3,3 & 2,5 & 1,0 & 3,5 & 2,1 \\
18:1 oléico & - & 42,0 & 16,7 & 23,8 & 8,9 & 28,4 & 21,3 & 8,9 & 31,6 & 15,9 \\
18:2 linoléico & - & 8,4 & 2,5 & 4,7 & 1,4 & 5,3 & 4,0 & 1,7 & 6,2 & 2,7 \\
18:3 linolênico & - & 0,2 & - & - & - & - & - & - & - & - \\
20:0 araquídico & - & 0,4 & 0,1 & 0,2 & 0,1 & 0,2 & 0,2 & 0,1 & 0,3 & 0,1 \\
21:0 & - & - & 0,1 & - & - & - & - & - & - & 0,1 \\
22:1 erúcico & - & - & 0,2 & - & - & - & - & - & - & - \\
\hline
\end{tabular}


graxos saturados (53,3\% e 18,3\%, respectivamente), confirmando os resultados obtidos por Gioielli, Baruffaldi (1988). Os resultados da Tabela III para as amostras 2, 3 e 6 estiveram muito próximos aos obtidos por Grimaldi (1999). Para a gordura de palma, foi obtido teor de ácido oléico na posição sn-2 igual a $65,9 \%$, enquanto que o citado autor obteve $63,6 \%$. Para a gordura de palmiste, a quantidade de ácidos láurico e mírístico encontrada nesta posição foi de $53,3 \%$ e $18,3 \%$, enquanto o citado autor obteve $52,5 \%$ e $16,6 \%$, respectivamente. Para a amostra 6 (50:50 palma/palmiste) houve predominância do ácido oléico nesta posição, com $41,5 \%$, enquanto o citado autor obteve 42,3\%. Lipp e Anklam (1998) relataram que na posição sn-2 do óleo de palma o ácido oléico é claramente predominante, seguido por quantidades aproximadamente iguais dos ácidos palmítico e linoléico. Sambanthamurthi, Sundram e Tan (2000) obtiveram a seguinte distribuição estereoespecífica percentual dos ácidos graxos no óleo de palma da Malásia: 14:0 (sn-2: 0,96; sn-1,3: 1,42); 16:0 (sn-2: 16,03; sn-1,3: 62,77); 18:0 (sn-2: 1,37; sn-1,3: 5,73); 18:1 (sn-2: 62,68; sn-1,3: 24,52) e 18:2 (sn-2: 18,95; sn-1,3: 5,52).

A Figura 1 evidencia o aumento do teor de ácidos graxos saturados na posição sn-2 das amostras, em decorrência da interesterificação química.

$\mathrm{Ng}$ (1985) analisou a distribuição posicional dos ácidos graxos no óleo de palma pela espectroscopia de ressonância nuclear magnética do ${ }^{13} \mathrm{C}$ e comparou os resultados àqueles obtidos através da hidrólise enzimática. Na posição sn-2, os valores percentuais encontrados através do método de RNM para os grupos acil saturados, ácidos oléico e linoléico foram: 18,8; 64,6 e 16,6, respectivamente; enquanto que, através do método de hidrólise enzimática seguida de cromatografia gasosa, os valores percentuais para estes mesmos grupamentos acil foram: 19,1; 60,5 e 19,7, respectivamente.

Lee e Foglia (2000) pesquisaram a síntese, purificação e cararacterização de lipídios estruturados produzidos a partir de gordura de frango e ácido caprílico, empregando a técnica de ressonância nuclear magnética ${ }^{13} \mathrm{C}$ para a determinação da análise posicional dos ácidos graxos nos triacilgliceróis. Estes autores relataram que, para a gordura de frango, 61 e 76\% dos grupos acil insaturados estão localizados nas posições sn-1,3 e sn-2, respectivamente. Para os lipídios estruturados, o conteúdo de ácidos graxos saturados nas posições sn- 1,3 foi de $62 \%$, comparado a $39 \%$ para a gordura de frango, indicando que o ácido caprílico foi preferencialmente incorporado na posição sn-1,3 da gordura de frango. Entre estas duas posições, a maior parte do ácido caprílico foi incorporada à posição sn-3. O conteúdo de ácidos graxos saturados na posição sn-2 também aumentou de 23,8 para $34,5 \%$ após a transesterificação, sugerindo que ocorreu migração acil de ácidos graxos saturados para a posição sn-2 durante a reação.

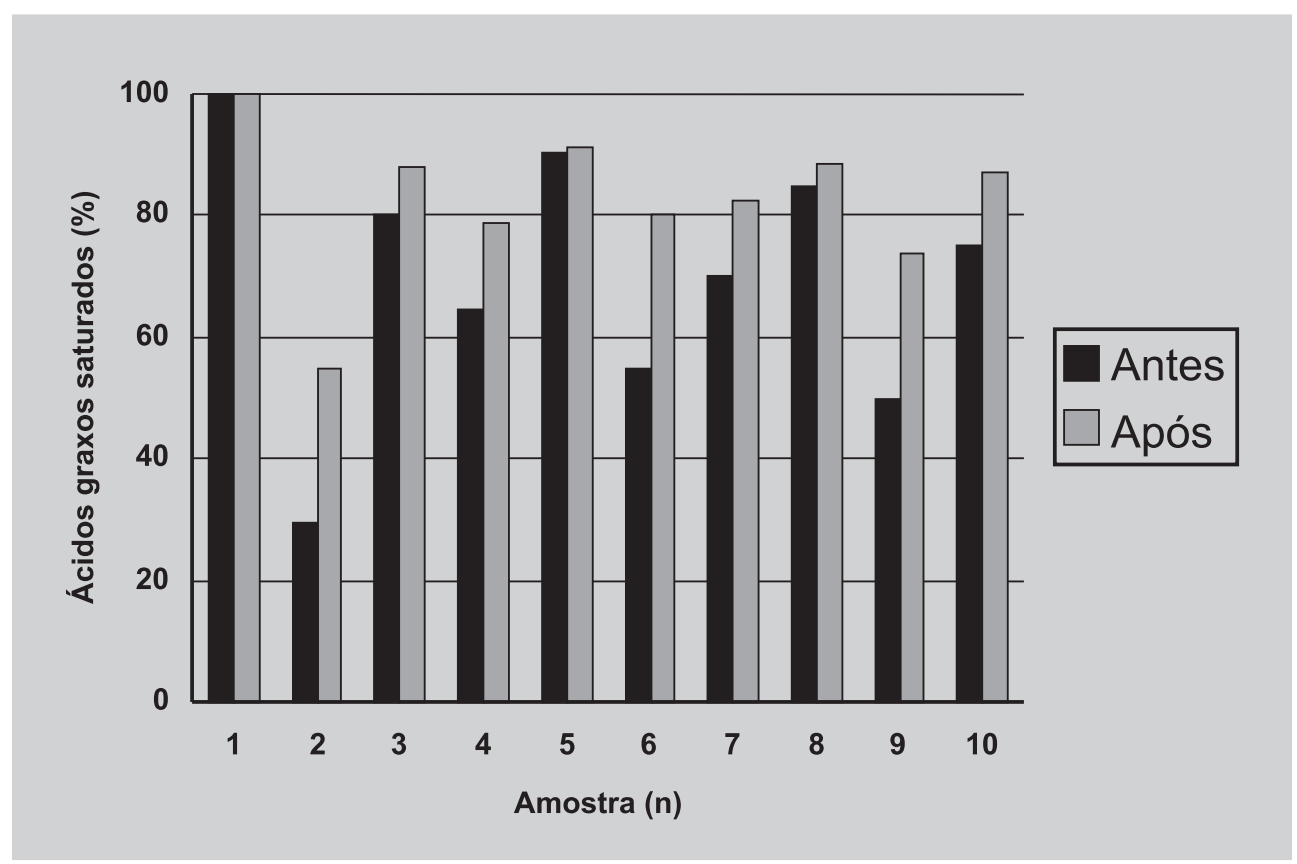

FIGURA 1 - Ácidos graxos saturados na posição sn-2 das amostras, antes e após a interesterificação. 
TABELA III - Composição em ácidos graxos na posição sn-2 (\%) das gorduras individuais e das misturas binárias e ternárias

\begin{tabular}{lcccccccccc}
\hline Ácidos & \multicolumn{10}{c}{ Amostras $\left(\mathrm{N}^{\circ}\right)$} \\
\cline { 2 - 11 } graxos (\%) & 1 & 2 & 3 & 4 & 5 & 6 & 7 & 8 & 9 & 10 \\
\hline $8: 0$ & 39,1 & 0,1 & 0,4 & 19,5 & 19,7 & 0,3 & 13,2 & 26,2 & 6,7 & 6,8 \\
$10: 0$ & 58,7 & - & 1,4 & 29,3 & 30,0 & 0,7 & 20,0 & 39,3 & 10,0 & 10,7 \\
$12: 0$ & 1,4 & 0,1 & 53,3 & 0,8 & 27,3 & 26,6 & 18,3 & 9,8 & 9,2 & 35,7 \\
$14: 0$ & 0,8 & 0,6 & 18,3 & 0,7 & 9,6 & 9,5 & 6,6 & 3,7 & 3,6 & 12,4 \\
$16: 0$ & - & 26,3 & 6,0 & 13,2 & 3,0 & 16,1 & 10,8 & 5,4 & 18,5 & 8,4 \\
$18: 0$ & - & 2,2 & 0,9 & 1,1 & 0,5 & 1,6 & 1,0 & 0,5 & 1,6 & 1,0 \\
$18: 1$ & - & 65,9 & 17,2 & 32,9 & 8,6 & 41,5 & 27,7 & 13,9 & 46,8 & 22,5 \\
$18: 2$ & - & 4,1 & 2,5 & 2,1 & 1,3 & 3,3 & 2,2 & 1,1 & 3,1 & 2,4 \\
$18: 3$ & - & 0,7 & - & 0,4 & - & 0,4 & 0,2 & 0,1 & 0,5 & 0,1 \\
\hline
\end{tabular}

TABELA IV - Composição em ácidos graxos na posição sn-2 (\%) das gorduras individuais interesterificadas e dos lipídios estruturados

\begin{tabular}{lcccccccccc}
\hline Ácidos & \multicolumn{10}{c}{ Amostras $\left(\mathrm{N}^{\circ}\right)$} \\
\cline { 2 - 11 } graxos (\%) & 1 & 2 & 3 & 4 & 5 & 6 & 7 & 8 & 9 & 10 \\
\hline $8: 0$ & 41,9 & - & 2,1 & 13,5 & 15,4 & 1,5 & 11,6 & 21,5 & 4,1 & 5,0 \\
$10: 0$ & 56,4 & - & 3,2 & 22,1 & 23,3 & 2,3 & 17,0 & 33,6 & 6,9 & 8,9 \\
$12: 0$ & 1,1 & - & 51,2 & 0,8 & 31,0 & 29,3 & 21,8 & 12,6 & 9,6 & 37,0 \\
$14: 0$ & 0,6 & 1,1 & 18,0 & 1,2 & 12,1 & 10,6 & 7,5 & 4,9 & 4,5 & 14,3 \\
$16: 0$ & - & 49,1 & 10,7 & 37,4 & 7,6 & 32,7 & 21,9 & 14,2 & 44,2 & 19,0 \\
$18: 0$ & - & 4,5 & 2,5 & 3,6 & 1,9 & 3,8 & 2,6 & 1,8 & 4,5 & 3,0 \\
$18: 1$ & - & 38,5 & 10,9 & 18,3 & 7,7 & 17,2 & 15,1 & 9,7 & 22,6 & 11,1 \\
$18: 2$ & - & 6,8 & 1,4 & 3,1 & 1,0 & 2,6 & 2,5 & 1,7 & 3,6 & 1,7 \\
\hline
\end{tabular}

As Tabelas V e VI mostram a proporção percentual de cada ácido graxo na posição sn-2 das amostras. Estas proporções foram calculadas segundo a seguinte equação (Gioielli, Baruffaldi, 1988):

Proporção $(\%)=\frac{(\%) \text { ácidos graxos na posição sn-2 }}{(\%) \text { ácidos graxos no triacilglicerol.3 }} \cdot 100$

Analisando os resultados da Tabela V, ou seja, valores obtidos antes da interesterificação química, observa-se que os triacilgliceróis de cadeia média apresentaram proporções dos ácidos caprílico (8:0) e cáprico (10:0) próximas de $33,3 \%$, o que permite verificar que estes produtos foram obtidos por esterificação química. Para as gorduras de palma e de palmiste observa-se que os ácidos palmítico e esteárico têm preferência pelas posições sn- 1 e sn-3, uma vez que na posição sn-2 seus valores foram inferiores a
$33,3 \%$. No caso da gordura de palmiste, os ácidos láurico e mirístico apresentaram preferência pela posição central do glicerol (38,4\% e 38,9\%, respectivamente). Por outro lado, o ácido oléico mostrou preferência pela posição sn2 na gordura de palma (52,3\%). Este padrão de distribuição é típico de óleos e gorduras vegetais naturais (Gioielli, 1998).

Analisando os resultados da Tabela VI, ou seja, valores obtidos após a interesterificação química, observase que as proporções de cada ácido graxo na posição sn2 , de modo geral, não estiveram em torno de $33,3 \%$, o que teoricamente deveria ter ocorrido por tratar-se de uma randomização. Entretanto, por tratar-se de resultados experimentais, ocorreram variações que podem estar associadas às diferenças de reatividade dos ácidos graxos, uma vez que há grande variação no comprimento das cadeias carbônicas das gorduras utilizadas neste estudo. O ácido 
TABELA V - Proporção percentual de cada ácido graxo na posição sn-2 das gorduras individuais e das misturas binárias e ternárias

\begin{tabular}{lcccccccccc}
\hline Ácidos & \multicolumn{10}{c}{ Amostras $\left(\mathrm{N}^{\circ}\right)$} \\
\cline { 2 - 10 } graxos (\%) & 1 & 2 & 3 & 4 & 5 & 6 & 7 & 8 & 9 & 10 \\
\hline $8: 0$ & 25,3 & - & 4,4 & 28,6 & 25,6 & 5,6 & 28,2 & 23,9 & 26,6 & 20,4 \\
$10: 0$ & 41,2 & - & 14,6 & 47,0 & 44,1 & 13,0 & 46,3 & 43,1 & 46,3 & 36,4 \\
$12: 0$ & - & - & 38,4 & - & 35,0 & 35,5 & 35,9 & 35,1 & 37,4 & 34,6 \\
$14: 0$ & - & - & 38,9 & - & 36,8 & 38,2 & 36,7 & 38,5 & 36,4 & 37,9 \\
$16: 0$ & - & 20,2 & 21,3 & 18,3 & 20,0 & 21,0 & 19,3 & 20,7 & 19,9 & 22,0 \\
$18: 0$ & - & 16,7 & 12,0 & 15,3 & 12,8 & 16,2 & 13,3 & - & 15,2 & 15,9 \\
$18: 1$ & - & 52,3 & 34,3 & 46,1 & 32,2 & 48,7 & 43,3 & 52,1 & 49,4 & 47,2 \\
$18: 2$ & - & 16,3 & 33,3 & 14,9 & 31,0 & 20,8 & 18,3 & 21,6 & 16,7 & 29,6 \\
\hline
\end{tabular}

TABELA VI - Proporção percentual de cada ácido graxo na posição sn-2 das gorduras individuais interesterificadas e dos lipídios estruturados

\begin{tabular}{lcccccccccc}
\hline $\begin{array}{l}\text { Ácidos } \\
\text { graxos (\%) }\end{array}$ & 1 & 2 & 3 & 4 & 5 & 6 & 7 & 8 & 9 & 10 \\
\cline { 2 - 10 } & 27,1 & - & 23,3 & 19,8 & 20,0 & 27,8 & 24,8 & 19,6 & 16,3 & 15,0 \\
$10: 0$ & 39,6 & - & 33,3 & 35,4 & 34,2 & 42,6 & 39,4 & 36,8 & 31,9 & 30,3 \\
$12: 0$ & - & - & 36,9 & - & 39,7 & 39,1 & 42,7 & 45,2 & 39,0 & 35,9 \\
$14: 0$ & - & - & 38,2 & - & 46,4 & 42,6 & 41,7 & 51,0 & 45,5 & 43,7 \\
$16: 0$ & - & 37,6 & 37,9 & 51,9 & 50,7 & 42,6 & 39,0 & 54,4 & 47,5 & 49,9 \\
$18: 0$ & - & 34,1 & 33,3 & 50,0 & 48,7 & 38,4 & 34,7 & - & 42,9 & 47,6 \\
$18: 1$ & - & 30,6 & 21,8 & 25,6 & 28,8 & 20,2 & 23,6 & 36,3 & 23,8 & 23,3 \\
$18: 2$ & - & 27,0 & 18,7 & 22,0 & 23,8 & 16,4 & 20,8 & 33,3 & 19,4 & 21,0 \\
\hline
\end{tabular}

cáprico (10:0), por exemplo, sempre demonstrou maior preferência pela posição sn-2 em relação ao ácido caprílico (8:0). Os ácidos palmítico e esteárico sempre tiveram aumentadas as suas presenças na posição sn-2, embora em proporções superiores a 33,3\%. Já o ácido oléico sempre teve diminuída sua presença nesta posição, apesar de em proporção inferior a 33,3\%. Diferenças na reatividade de ácidos graxos específicos e variação nas velocidades de esterificação têm sido usadas para explicar a possível ocorrência de randomização incompleta (Willis, Lencki, Marangoni, 1998). Estas variações também foram verificadas por Grimaldi (1999) em gorduras de palma e palmiste interesterificadas. Após a interesterificação, os ácidos graxos saturados aumentaram sua participação na posição central do triacilglicerol. Para o óleo de palma, foi observado considerável aumento do teor de ácido palmítico na posição sn-2, devido ao rearranjo randômico.
As Tabelas VII e VIII mostram a composição percentual calculada dos grupos de triacilgliceróis. Os valores de trissaturados (SSS), após a reação de interesterificação aumentaram apenas para o óleo de palma, indo de $10,3 \%$ para $12,0 \%$, provocando aumento da consistência e do ponto de fusão do produto interesterificado. Grimaldi (1999) obteve aumento de $8,7 \%$ para $12,5 \%$ para este mesmo grupo. Nas demais amostras, geralmente notou-se sua redução, principalmente na mistura 4 , que apresentou decréscimo de $55,2 \%$ para $36,5 \%$. No caso do óleo de palmiste, os valores dos grupos de triacilgliceróis não sofreram grandes variações após a interesterificação. Contudo, Laning (1985) mencionou que, após o rearranjo, o ponto de fusão do óleo de palmiste é reduzido devido ao aumento da concentração dos triacilgliceróis com grau intermediário de insaturação, tornando esta fração mais plástica. 
TABELA VII - Composição percentual calculada dos grupos de triacilgliceróis nas gorduras individuais e nas misturas binárias e ternárias

\begin{tabular}{lcccccccccc}
\hline Grupos & \multicolumn{10}{c}{ Amostras $\left(\mathrm{N}^{\circ}\right)$} \\
\cline { 2 - 10 }$(\%)$ & 1 & 2 & 3 & 4 & 5 & 6 & 7 & 8 & 9 & 10 \\
\hline SSS & 100 & 10,3 & 52,4 & 55,2 & 76,2 & 31,4 & 54,2 & 77,1 & 32,3 & 53,3 \\
SSI & - & 39,0 & 37,7 & 19,6 & 18,9 & 38,5 & 25,6 & 12,7 & 32,3 & 31,7 \\
SII & - & 39,0 & 9,2 & 19,6 & 4,7 & 24,1 & 16,0 & 8,1 & 27,5 & 12,6 \\
III & - & 11,7 & 0,7 & 5,9 & 0,4 & 6,2 & 4,1 & 2,1 & 7,9 & 2,4 \\
\hline
\end{tabular}

Onde: $\mathrm{SSS}=$ trissaturados; $\mathrm{SSI}=$ dissaturados monoinsaturados; $\mathrm{SII}=$ monossaturados diinsaturados; $\mathrm{III}=$ triinsaturados

TABELA VIII - Composição percentual calculada dos grupos de triacilgliceróis nas gorduras individuais interesterificadas e nos lipídios estruturados

\begin{tabular}{lcccccccccc}
\hline Grupos & \multicolumn{10}{c}{ Amostras $\left(\mathrm{N}^{\circ}\right)$} \\
\cline { 2 - 11 }$(\%)$ & 1 & 2 & 3 & 4 & 5 & 6 & 7 & 8 & 9 & 10 \\
\hline SSS & 100 & 12,0 & 52,5 & 36,5 & 72,3 & 29,0 & 41,6 & 71,4 & 24,0 & 53,7 \\
SSI & - & 36,9 & 37,8 & 43,8 & 24,9 & 44,4 & 42,3 & 25,5 & 43,8 & 37,2 \\
SII & - & 38,1 & 9,0 & 17,4 & 2,7 & 22,8 & 14,4 & 3,0 & 26,7 & 8,4 \\
III & - & 13,0 & 0,7 & 2,3 & 0,1 & 3,8 & 1,7 & 0,1 & 5,5 & 0,7 \\
\hline
\end{tabular}

Onde: $\mathrm{SSS}=$ trissaturados; $\mathrm{SSI}=$ dissaturados monoinsaturados; $\mathrm{SII}=$ monossaturados diinsaturados; $\mathrm{III}=$ triinsaturados

Em margarinas, associa-se a formação de grumos à relação triacilgliceróis assimétricos/simétricos. Quanto maior esta razão maior será a possibilidade de ocorrer arenosidade no produto. O óleo de palma é caracterizado pela presença de triacilglceróis do tipo OOO, PLO, POL, PLP, PPP, POP e POO (Lipp, Anklam, 1998). Os óleos de palmiste e de coco podem ser modificados para utilização como substitutos da manteiga de cacau e, devido à incompatibilidade no estado sólido, são adequados para substituição de $100 \%$ da manteiga de cacau (Lipp, Anklam, 1998). A interesterificação do óleo de palma com óleos láuricos pode levar à formação de arenosidade. Esta ocorrência pode ser atribuída à formação de esferas de $0,5 \mathrm{~mm}$ de diâmetro ao redor dos núcleos de cristais (Grimaldi, 1999). Misturas de óleo de palma com gorduras láuricas diminuem o teor de triacilgliceróis trissaturados após a interesterificação química. Isto foi observado para a amostra 6 , cujos valores de trissaturados passaram de $31,4 \%$ para $29,0 \%$, após a interesterificação. Estes dados estão de acordo com os encontrados por Grimaldi (1999), que observou valores de $32,0 \%$ e $29,8 \%$, para esta mesma mistura.

\section{CONCLUSÕES}

Antes do rearranjo ao acaso observou-se preferência do ácido oléico pela posição sn-2, enquanto que os ácidos palmítico e esteárico distribuiram-se principalmente pelas posições sn-1 e sn-3. Nos lipídios estruturados, os ácidos palmítico e esteárico aumentaram sua participação na posição central do triacilglicerol, enquanto o ácido oléico apresentou diminuição nesta mesma posição.

\section{ABSTRACT \\ Stereospecific distribution of structured lipids obtained from palm oil, palm kernel oil, and medium chain triacylglycerols}

Structured lipids were synthesized by chemical interesterification from palm oil, palm kernel oil, and medium chain triacylglycerols. The objective of this study was to verify the fatty acids positional distribution in the structured lipids. It was possible to confirm the interesterification occurrence through enzymatic hydrolysis, which allowed to know the fatty acids composition in specific positions of the triacylglycerols. Ten samples composed by three individual samples, three binary mixtures and four ternary mixtures were studied. The samples were hydrolyzed with swine pancreatic lipase at $40^{\circ} \mathrm{C}$ and then analyzed for the fatty acid composition by gas chromatography. From the experimental results, 
the groups of triacylglycerols in the individual samples and in the mixtures, obtained before and after the interesterification reaction, were calculated. The 1,3random, 2-random and the 1,2,3-random theories were utilized. The results showed that before the random rearrangement, oleic acid was mainly esterified to the sn2 position, whereas palmitic and stearic acids were mainly distributed at the sn-1 and sn-3 positions. The saturated fatty acids in the structured lipids increased their participation in the triacylglycerol central position, whereas the unsaturated fatty acids were decreased at the same position.

UNITERMS: Stereospecific Distribution. Enzymatic hydrolysis. Palm oil and palm kernel oil. Medium chain triacylglycerols. Chemical interesterification. Structured lipids.

\section{AGRADECIMENTOS}

À Fundação de Amparo à Pesquisa do Estado de São Paulo - FAPESP, ao Conselho Nacional de Desenvolvimento Científico e Tecnológico - CNPq e à Coordenação de Aperfeiçoamento de Pessoal de Nível Superior - CAPES, pelo auxílio financeiro e pelas bolsas concedidas aos autores.

\section{REFERÊNCIAS BIBLIOGRÁFICAS}

ANTONIOSI FILHO, N. R. Análise de óleos e gorduras vegetais utilizando métodos cromatográficos de alta resolução e métodos computacionais. São Carlos, 1995, 340p. [Tese de Doutorado. Instituto de Química, Universidade de São Paulo].

BRASIL. Leis, decretos, etc. Portaria SVS/MS. Resolução n ${ }^{\circ}$ 129/99 da Comissão Nacional de Normas e Padrões para Alimentos. In: COMPÊNDIO da legislação de alimentos: consolidação das normas e padrões de alimentos. São Paulo: ABIA, 1999. Seção: 1, p.23-29.

CARNIELLY, V. P., LUIJENDIJK, I. H. T., VAN GOUDOEYER, J. B., SULKERS, E. J., BOERLAGE, A. A., DEGENHART, H. J., SAUER, P. J. J. Feeding premature newborn infants palmitic acid in amounts and stereochemical position similar to that of human milk: effects on fat and mineral balance. Am. J. Clin. Nutr., New York, v.61, p. 1037-1042, 1995.

CHRISTIE, W. W. Lipid analysis. 2. ed. Oxford: Pergamon Press, 1982, p. 155-166.
D’AGOSTINI, D., FERRAZ, R. C., GIOIELLI, L. A. Consistência de misturas binárias e ternárias de gorduras de palma, palmiste e triacilgliceróis de cadeia média. Rev. Bras. Ciênc. Farm., São Paulo, v.36, n.1, p.147-155, 2000.

D’AGOSTINI, D., FERRAZ, R.C., GIOIELLI, L.A., SOTERO SOLIS, V.E. Lípidos estructurados obtenidos por interesterificación de las mezclas binarias y ternarias de las grasas de palma, semilla de palma y triglicéridos de cadena media. Grasas Aceites, Sevilla, v. 52, n. 3/4, p. 214-221, 2001.

D'AGOSTINI, D., FERRAZ, R.C., SOTERO SOLIS, V.E., GIOIELLI, L.A. Contenido de grasa sólida de las mezclas binarias y ternarias de aceite de palma, aceite de semilla de palma y triacilgliceroles de cadena media. Alimentaria, Madrid, v. 38, n. 324, p. 47-53, 2001 a.

D’AGOSTINI, D., GIOIELLI, L.A., FERRAZ, R.C. Pontos de amolecimento e de fusão e viscosidade de misturas binárias e ternárias de gorduras de palma e de palmiste e triacilgliceróis de cadeia média. Rev. Port. Farm., Coimbra, v. 50, n. 4, p. 161-170, 2000.

DECKER, E. A. The role of stereospecific saturated fatty acid positions on lipid nutrition. Nutr. Rev., Lawrence, v.54, n.4, p.108-110, 1996.

GEORGE, S., ARUMUGHAN, C. Positional distribution of fatty acids in the triacylglycerols of developing oil palm fruit. J. Am. Oil Chem. Soc., Champaign, v.70, n.12, p.1255-1258, 1993.

GIOIELLI, L.A. Interesterificação de óleos e gorduras. Rev. Eng. Alim., São Paulo, v.4, n.21, p. 22-24, 1998.

GIOIELLI, L.A. Lipídios estruturados. In: CURI, R., POMPÉIA, C., MIYASAKA, C.K., PROCÓPIO, J., eds. Entendendo a gordura: os ácidos graxos. São Paulo: Manole, 2002. p. 457-465.

GIOIELLI, L. A., BARUFFALDI, R. Acompanhamento da reação de interesterificação de gordura de babaçu e azeite de dendê. Rev. Farm. Bioquím. Univ. S. Paulo, São Paulo, v.24, n.1, p.29-38, 1988.

GOH, E. M. Formulation of lauric oil-containing food products and their performance. In: WORLD CONFERENCE ON LAURIC OILS: SOURCES, PROCESSING AND APPLICATIONS, 1, 1994. Champaign: AOCS Press, 1994. p. 98-103. 
GRIMALDI, R. Alternativas tecnológicas para produção de gorduras especiais. Campinas, 1999. 162p. [Tese de Doutorado. Faculdade de Engenharia de Alimentos, Universidade Estadual de Campinas].

GUNSTONE, F. D., HARWOOD, J. L., PADLEY, F. B. The lipid handbook. 2. ed. London: Chapman \& Hall, 1994. 551p.

HARP, T. K., HAMMOND, E. G. Stereospecific analysis of soybean triacylglycerols. Lipids, Champaign, v.33, n.2, p.209-216, 1998.

HAUMANN, B. F. Tools: hydrogenation, interesterification. Inform, Champaign, v.5, p.668-678, 1994.

HAUMANN, B. F. Structured lipids allow fat tailoring. Inform, Champaign, v.8, n.10, p.1004-1011, 1997.

KRITCHEVSKY, D., TEPPER, S. A., CHEN, S. C., MEIJER, G. W., KRAUSS, R. M. Cholesterol vehicle in experimental atherosclerosis. 23. Effects of specific synthetic triglycerides. Lipids, Champaign, v.35, n.6, p.621-625, 2000.

LANING, S. J. Chemical interesterification of palm, palm kernel and coconut oil. J. Am. Oil Chem. Soc., Champaign, v.62, p.400-405, 1985.

LEE, K. T., FOGLIA, T. A. Synthesis, purification, and characterization of structured lipids produced from chicken fat. J. Am. Oil Chem. Soc., Champaign, v.77, n.10, p. 1027-1034, 2000.

LIE KEN JIE, M. S. F., MUSTAFA, J. High resolution nuclear magnetic resonance spectroscopy-applications to fatty acids and triacylglycerols. Lipids, Champaign, v.32, n.10, p.1019-1034, 1997.

LIPP, M., ANKLAM, E. Review of cocoa butter and alternative fats for use in chocolate - Part A. Compositional data. Food Chem., v. 62, n.1, p.73-97, 1998.

MANSOUR, M. P., SINCLAIR, A. J. The trans fatty acid and positional (sn-2) fatty acid composition of some Australian margarines, dairy blends and animal fats. Asia Pacific J. Clin. Nutr., Geelong, v.2, n.4, p.155-163, 1993.
MU, H., XU, X., HOY, C. E. Production of specific structured triacylglycerols by lipase catalyzed interesterification in a laboratory scale continuous reactor. J. Am. Oil Chem. Soc., Champaign, v.75, n.9, p.1187-1193, 1998.

$\mathrm{NG}, \mathrm{S}$. Analysis of positional distribution of fatty acids in palm oil by ${ }^{13} \mathrm{C}$ NMR spectroscopy. Lipids, Champaign, v.20, n.11, p.778-782, 1985.

NORAINI, I., EMBONG, M. S., AMINAH, A., ALI, M. D., MAIMON, C. H. Physical characteristics of shortenings based on modified palm oil, milkfat, and low melting milkfat fraction. Fat Sci. Technol., Kuala Lumpur, v.97, n.7/8, p.253-260, 1995.

ONG, A. S. H., CHOO, Y. M., OOI, C. K. Developments in palm oil. In: HAMILTON, R.J.,ed. Developments in oils and fats. Liverpool:Blackie Academic \& Professional, 1995. p.153-191.

SAMBANTHAMURTHI, R., SUNDRAM, K., TAN, Y. A. Chemistry and biochemistry of palm oil. Progr. Lipid Res., Oxford, v.39, p.507-558, 2000.

SANDSTROM, R., HYLTANDER, A., KORNER, U., LUNDHOLM, K. Structured triglycerides to postoperative patients - a safety and tolerance study. $J$. Parent. Enter. Nutr., v.17, n.2, p.153-157, 1993.

WILLIS, W. M., LENCKI, R. W., MARANGONI, A. G. Lipid modification strategies in the production of nutritionally functional fats and oils. Crit. Rev. Food Sci. Nutr., v.38, n.8, p.639-674, 1998.

XU, X., SKANDS, A. R. H., HOY, C. E., MU, H., BALCHEN, S., NISSEN, J. A. Production of specific-structured lipids by enzymatic interesterification: elucidation of acyl migration by response surface design. J. Am. Oil Chem. Soc., Champaign, v.75, n.9, p.1179-1185, 1998.

YANKAH, V. V., AKOH, C. C. Lipase catalyzed acidolysis of tristearin with oleic or caprylic acids to produce structured lipids. J. Am. Oil Chem. Soc., Champaign, v.77, n.5, p.495-500, 2000.

ZEITOUN, M. A. M., NEFF, W. E., LIST, G. R., MOUNTS, T. L. Physical properties of interesterified fat blends. $J$. Am. Oil Chem. Soc., Champaign, v.70, n.5, p.467-471, 1993.

Recebido para publicação em 23 de abril de 2001. 